\title{
Gambaran histologik otot jantung pada hewan coba postmortem
}

\author{
${ }^{1}$ Tonci Ubruangge \\ ${ }^{2}$ Sunny Wangko \\ ${ }^{2}$ Sonny J. R. Kalangi
}

\author{
${ }^{1}$ Kandidat Skripsi Fakultas Kedokteran Universitas Sam Ratulagi Manado \\ ${ }^{2}$ Bagian Anatomi Histologi Fakultas Kedokteran Universitas Sam Ratulagi Manado \\ Email: tubruangge_11_305@yahoo.com
}

\begin{abstract}
Commonly, unnatural death is complicated and causes difficulties for to the investigating officers to reveal the modus operandi and the time of death. Estimation of postmortem interval is very important in the investigation, albeit, it is frequently put the investigators to a debate. This study aimed to obtain the histological changes of heart muscle at several time intervals postmortem. This was a descriptive observational study. A domestic pig weighed $\pm 20 \mathrm{~kg}$ was used as model. The pig was killed by conducting a blunt trauma at its occipital area. Heart muscle samples were taken at several time intervals as follows: 15 minutes, 30 minutes, 45 minutes, 60 minutes, 75 minutes, 90 minutes, 105 minutes, 2 hours, 3 hours, 4 hours, 5 hours, 6 hours, 12 hours, and 24 hours postmortem. The histological changes were observed with an Olympus CX21 microscope and Optilab. The percentages of those changes were evaluated at 5 high-power fields (400x) for each sample. The results showed that less than 30\% of myocytes had flattened and denser nuclei at 105 minutes postmortem and were associated with hydrophic degeneration at 2 hours postmortem. Those changes became widely spreaded and at 24 hours postmortem they could be identified in $60-80 \%$ of myocytes. Albeit, the striated pattern could still be identified until 24 hours postmortem. Conclusion: The histological changes of heart muscle postmortem namely morpholocical changes of the nuclei and hydrophic degeneration could be identified at 2 hours postmortem. At 24 hours postmortem those changes were distributed widely among the myocytes, however, the striated pattern could still be identified. Moreover, there were still focal areas with normal appearance.
\end{abstract}

Keywords: histological changes, cardiac muscle, postmortem

\begin{abstract}
Abstrak: Kematian tidak wajar yang dialami seseorang dengan berbagai motif kejahatan dapat menyulitkan para penyidik dalam menggungkapkan modus operandi dan waktu kematian. Penentuan lama kematian $\mathrm{k}$ orban sangat dibutuhkan dan sering menjadi perdebatan di peradilan. Penelitian ini bertujuan untuk mendapatkan perubahan histologik jaringan otot jantung hewan coba pada beberapa interval waktu postmortem. Jenis penelitian ialah deskriptif-observasional menggunakan hewan coba satu ekor babi lokal dengan berat badan $\pm 20 \mathrm{~kg}$. Hewan coba dimatikan dengan pukulan benda tumpul pada area osipital. Sampel otot jantung diambil pada beberapa interval waktu: 15 menit, 30 menit, 45 menit, 60 menit, 75 menit, 90 menit, 105 menit, 2 jam, 3 jam, 4 jam, 5 jam, 6 jam, 12 jam, dan 24 jam postmortem. Perubahan histologik diamati dengan mikroskop Olympus CX21 dan Optilab. Persentase perubahan tersebut dievaluasi pada 5 lapang pandang pembesaran 400x. Hasil penelitian mendapatkan $<30 \%$ miosit dengan inti yang memipih dan memadat pada 105 menit postmortem serta degenerasi hidropik 2 jam postmortem. Perubahanperubahan tersebut makin meluas dan pada 24 jam postmortem telah tampak pada 60-80\% miosit jantung tetapi corak seran lintang tetap dapat diidentifikasi. Simpulan: Perubahan histologik berupa perubahan morfologik inti disertai degenerasi hidropik mulai tampak pada 2 jam postmortem dan pada 24 jam postmortem perubahan tersebut telah terdistribusi luas. Walaupun demikian, pada 24 jam postmortem corak seran lintang masih dapat diidentifikasi. Juga terdapat area-area fokal dengan jaringan otot jantung yang masih tampak normal.
\end{abstract}

Kata kunci: perubahan histologik, otot jantung, postmortem 
Kasus kejahatan yang terjadi di Indonesia dari tahun ke tahun selalu mengalami peningkatan mulai dari perampokan sampai dengan pembunuhan ${ }^{1-3}$ Berbagai cara digunakan untuk mematikan korban antara lain dengan mutilasi yaitu pemisahan bagian-bagian tubuh atau organ dari korban. Tindakan ini dilakukan untuk mempersulit petugas dalam proses identifikasi, ${ }^{4}$ sehingga diperlukan berbagai cara untuk menetuka identifikasi dan saat kematian antara lain dengan patokan dari beberapa organ tubuh manusia yang telah mengalami perubahan postmortem.,

Sel merupakan unit struktural terkecil dalam tubuh manusia. Sel dapat beradaptasi dengan perubahan yang terjadi di sekitarnya sampai pada tahap tertentu kemudian sel tersebut akan mati. Kematian sel dibagi menjadi dua yaitu kematian sel yang diprogramkan oleh sel itu sendiri (apoptosis) dan kematian sel karena tidak mampu untuk beradaptasi dengan lingkungan sekitarnya misalnya pada keadaan iskemia berat dimana sel tidak memperoleh pasokan oksigen dan nutrisi yang cukup untuk memperbaiki dirinya yang berakibat terjadinya nekrosis dan kematian sel. ${ }^{7,8}$

\section{METODE PENELITIAN}

Jenis penelitian ini ialah deskriptifobservasional yang dilakukan di Bagian Anatomi-Histologi Fakultas Kedokteran Universitas Sam Ratulagi Manado dan Pusat Diagnostik Patologi Anatomi Manado. Hewan coba yang digunakan ialah satu ekor babi dengan berat $20 \mathrm{~kg}$.

Hewan coba dimatikan dengan cara dipukul di area osipital Setelah hewan coba berhenti bernafas, dicatat waktu kematian. Dilakukan pengambilan sampel otot jantung berukuran $0,5 \times 0,5 \times 0,5 \mathrm{~cm}^{3}$ dengan beberapa interval waktu, yaitu: 15 menit, 30 menit, 45 menit, 60 menit, 75 menit, 90 menit, 105 menit, 2 jam, 3 jam, 4 jam, 5 jam, 6 jam, 12 jam, dan 24 jam. Setiap sampel yang diambil kemudian difiksasi menggunakan formalin $10 \%$ dan disiapkan dalam botol yang diberi penamaan sesuai waktu pengambilannya. Sampel yang telah siap dibuat sediaan histologik di Pusat Diagnostik Patologi Anatomi (PDPA) Manado. Sediaan yang telah siap diidentifikasi dengan mikroskop cahaya dan dibuat mikrofoto dengan menggunakan optilab.

Perubahan mikroskopik yang diamati ialah ada tidaknya corak seran lintang dan perubahan mikroskopik pada miosit termasuk inti. Penilaian dilakukan pada 5 lapang pandang pembesaran 400x berdasarkan persentase.

\section{HASIL PENELITIAN}

Gambaran mikroskopik jaringan otot jantung pada 15 menit sampai dengan 90 menit postmortem memperlihatkan corak seran lintang dan miosit serta intinya yang tampak normal (Gambar 1).

Pada 105 menit postmortem sebagian kecil miosit memperlihatkan inti yang memipih dan memadat. Pada 2 jam postmortem sebagian kecil miosit tampak telah mengalami degenerasi hidropik (Gambar 2).

Pada 4-6 jam postmortem perubahan morfologik inti miosit dan adanya degenerasi hidropik berlangsung terus dan makin meluas pada sebagian miosit walaupun masih meninggalkan area-area yang tampak normal (Gambar 3). Pada 12 jam postmortem sebagian besar miosit jantung memperlihatkan inti yang memipih dan memadat serta degenerasi hidropik tetapi masih meninggalkan area-area yang tampak normal. Corak seran lintang dan struktur otot jantung masih dapat diidentifikasi sampai 24 jam postmortem (Gambar 4).

Persentase perubahan histologik dapat dilihat pada Tabel 1. 


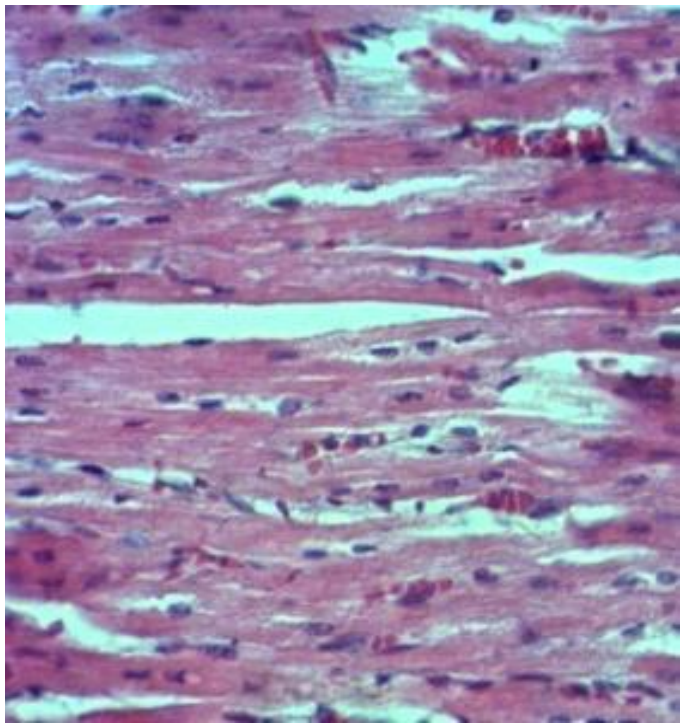

Gambar 1. Mikroskopik jaringan otot jantung babi 15 menit postmortem (400x). Corak seran lintang, miosit jantung, dan inti sel masih tampak normal.

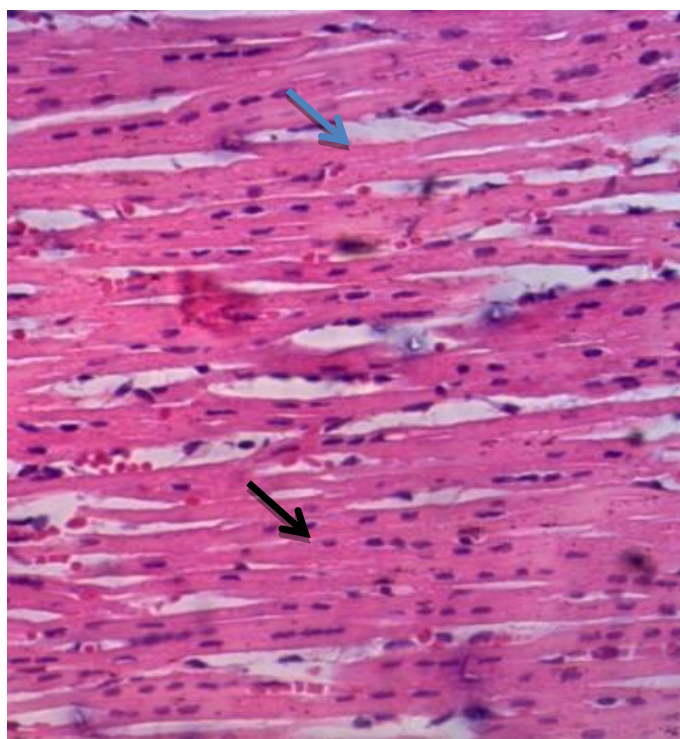

Gambar 3. Mikroskopik jantung babi 4 jam postmortem (400x). Corak seran lintang masih tampak. Sebagian miosit jantung telah mengalami degenerasi hidropik (panah biru). Inti sel tampak memipih dan memadat (panah hitam).

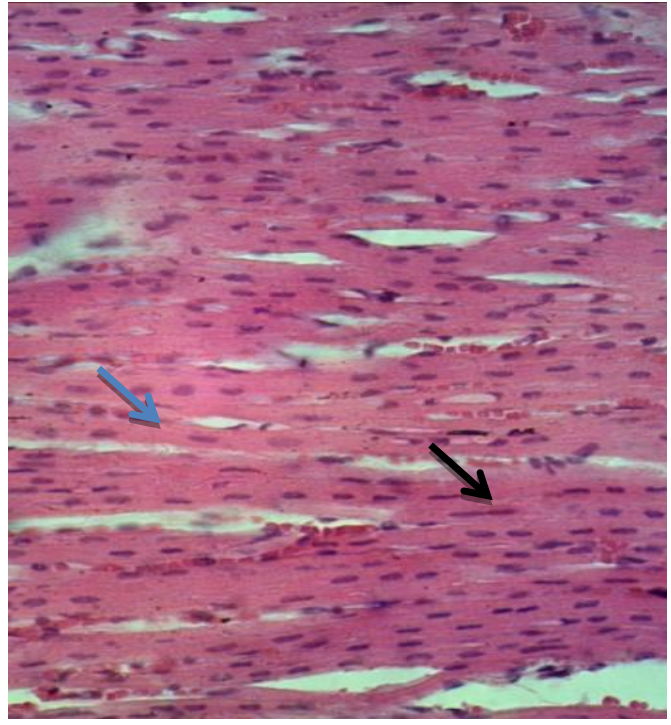

Gambar 2. Mikroskopik jantung babi 2 jam postmortem (400x). Corak seran lintang masih tampak. Sebagian kecil miosit jantung telah mengalami degenerasi hidropik (panah biru) serta inti sel mulai memipih dan memadat (panah hitam).

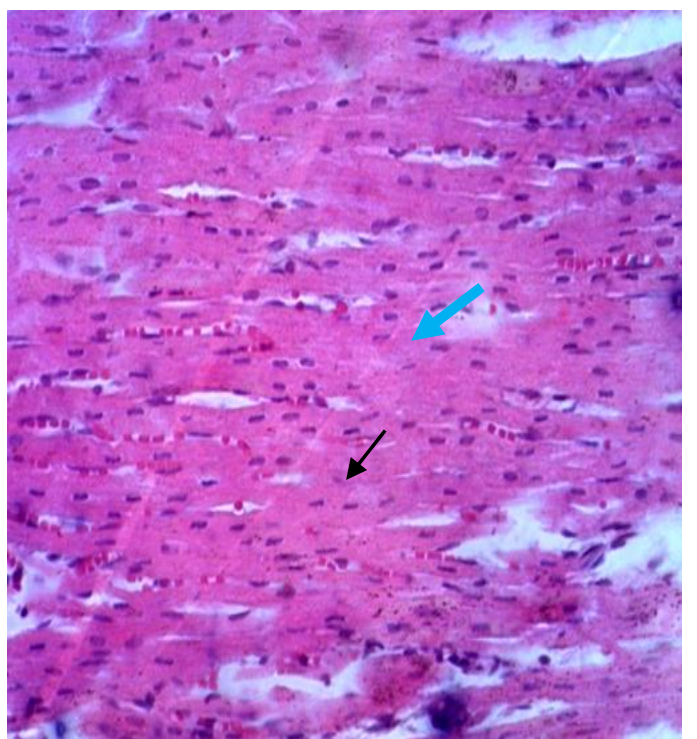

Gambar 4. Mikroskopik jantung babi 24 jam postmortem (400x). Corak seran lintang pada otot jantung masih dapat diidentifikasi. Sebagian besar inti telah memipih dan memadat (panah hitam), serta miosit yang mengalami degenerasi hidropik (panah biru). 
Ubruangge, Wangko, Kalangi: Gambaran histologik otot jantung pada ...

Tabel 1. Perubahan histologik pada jaringan otot jantung hewan coba postmortem

\begin{tabular}{lccc}
\hline Postmortem & Corak seran lintang & $\begin{array}{l}\text { Perubahan morfologik inti } \\
\text { (memipih dan memadat) }\end{array}$ & Degenerasi hidropik \\
\hline 15 menit & + & - & - \\
30 menit & + & - & - \\
45 menit & + & - & - \\
60 menit & + & - & - \\
75 menit & + & - & - \\
90 menit & + & - & - \\
105 menit & + & $<30 \%$ & - \\
2 jam & + & $<30 \%$ & $<30 \%$ \\
3 jam & + & $30-60 \%$ & $30-40 \%$ \\
4 jam & + & $30-60 \%$ & $30-40 \%$ \\
5 jam & + & $30-60 \%$ & $30-40 \%$ \\
6 jam & + & $60-80 \%$ & $40-60 \%$ \\
12 jam & + & $60-80 \%$ & $60-80 \%$ \\
24 jam & + & & \\
& & & \\
\hline
\end{tabular}

\section{BAHASAN}

Penelitian ini bertujuan untuk melihat perubahan mikroskopik jaringan otot jantung pada hewan coba postmortem. Hewan coba yang digunakan yaitu satu ekor babi lokal (Sus domestica) dengan berat $\pm 20 \mathrm{~kg}$. Babi dipilih sebagai hewan coba karena mempunyai karakteristik anatomi dan fisiologi yang hampir sama dengan manusia. ${ }^{9}$

Mahkluk hidup yang telah mati akan mengalami perubahan sehingga memberkan gambaran secara kasat mata (perubahan secara makroskopik) dan juga tidak kasat mata (secara mikroskopik). Pada postmortem aliran darah yang memasok oksigen ke seluruh tubuh terhenti sehingga akan tampak perubahan secara mikroskopik yaitu sel-sel yang mengalami nekrosis yang kemudian berlanjut pada kematian sel. ${ }^{10,11}$

Sel yang mengalami nekrosis akan memberikan gambaran inti menyusut, batasnya tidak teratur dan berwarna gelap; proses ini disebut piknosis sedangkan inti nya disebut piknotik. Perubahan selanjutnya yaitu karioreksis dimana inti sel hancur dan meninggalkan pecahan-pecahan zat kromatin yang tersebar di dalam sel dan pada akhirnya inti sel akan menghilang (kariolisis). ${ }^{10,11}$

Pada 15 menit sampai dengan 90 menit postmortem gambaran histologik otot jantung babi tampak normal. Perubahan histologik yang paling awal diamati dimulai pada 105 menit postmortem dimana sebagian kecil inti tampak memipih dan memadat yang menunjukkan mulai terjadinya nekrosis (piknosis). Pada 2 jam postmortem sebagian kecil miosit jantung (<30\%) memperlihatkan tanda degenerasi hidropik karena terjadi perembesan cairan intersel ke dalam miosit walaupun secara keseluruhan jaringan otot jantung masih tampak normal.

Pada 2 jam sampai dengan 6 jam perubahan histologik otot jantung tidak banyak berbeda; yang terjadi berupa bertambahnya miosit yang mengalami degenerasi hidropik dan gambaran inti yang memipih dan memadat. Pada 12 jam dan 24 jam postmortem persentase gambaran inti yang memipih dan memadat serta miosit yang mengalami degenerasi hidropik bertambah walaupun masih terlihat areaarea dengan gambaran jaringan otot jantung yang tampak normal. Sebagian miosit tampak homogen; kemungkinan karena hilangnya partikel glikogen pada sel. ${ }^{10,12}$

Penelitian terdahulu yang dilakukan oleh Pratama ${ }^{13}$ yang meneliti hubungan kematian dengan kerusakan pada otot jantung tikus Wistar dengan interval waktu 0 jam sampai 4 jam postmortem tidak 
mendapatkan perubahan berupa nekrosis otot jantung hewan coba. Pada penelitian lain yang dilakukan oleh Prasojo ${ }^{14}$ mengenai hubungan antara lama kematian dengan kerusakan histopatologik musculus gastrocnemius tikus Wistar dengan beberapa interval waktu yaitu pada 0 jam sampai 4 jam postmortem mendapatkan tidak ada perubahan nekrosis ataupun inti yang piknotik pada $m$. gastrocnemius tikus Wistar sampai dengan 4 jam posmortem.

Schoen dan Mitchell ${ }^{15}$ menyatakan bahwa pada infark miokard $1 / 2-4$ jam postmortem belum tampak perubahan mikrsokopik yang berarti. Pada 4-12 postmortem mulai tampak nekrosis koagulasi, edema, dan perdarahan. Pada 1224 jam postmortem nekrosis sel berlangsung terus, dan tampak inti piknotik. Pada penelitian ini diawali dengan kematian hewan coba yang memperlihatkan hasil yang berbeda dengan perjalanan perubahan histologik otot jantung pada kasus infark miokard. Perubahan histologik berupa perubahan morfologik inti miosit pada 105 menit postmortem dan adanya degenerasi hidropik miosit jantung pada 2 jam postmortem diharapkan dapat menjadi pertimbangan pada kasus kematian yang dicurigai akibat infark miokard pada autopsi.

Penelitian yang dilakukan oleh Rahmadana $^{16}$ mengenai gambaran histologik ginjal postmortem pada hewan coba babi dengan beberapa interval waktu mendapat-kan bahwa telah terjadi perubahan berupa nekrosis dan kariolisis pada tubuli distal dan proksimal ginjal hewan coba 60 menit postmortem. Hal ini berbeda dengan hasil penelitian ini yang mendapatkan perubahan pada sebagian kecil miosit berupa degenerasi hidropik dan perubahan morfologik inti 2 jam postmortem. Pada 12 jam dan 24 jam postmortem, meskipun telah terjadi perubahan histologik pada miosit jantung, struktur mikroskopik jatringan otot jantung masih dapat diidentifikasi dengan cukup jelas. Walaupun tanda awal kematian sel menuju inti piknotik sudah tampak tetapi karioreksis maupun kariolisis belum tampak jelas.
Berdasarkan hasil penelitian ini dapat disimpulkan bahwa jaringan otot jantung masih dapat diidentifikasi secara histologik walaupun telah terjadi kematian selama 24 jam. Hal ini berbeda dengan hasil penelitian Rahmadana et al. ${ }^{16}$ mengenai perubahan mikroskopik pada ginjal hewan coba postmortem pada beberapa interval waktu. Adanya perbedaan ini justru mempunyai nilai tambah yang diharapkan dapat menjadi pembanding pada waktu menentukan saat kematian. Organ jantung relatif lebih resistem terhadap autolisis dan dekomposisi dibandingkan dengan organ lainnya; hal ini mungkin disebabkan karena struktur jantung yang sebagian besar terdiri dari miofibril (jaringan otot), sitoplasma padat dan kaya dengan mitokondria. ${ }^{13}$

Hasil penelitian ini diharapkan dapat menjadi penelitian awal agar dapat mengaplikasikan hewan coba dalam menentukan saat kematian sebagai pembanding, terutama pada kasus kematian tidak wajar dengan organ atau anggota tubuh yang rusak sebagian sehingga tanda-tanda kematian sulit dievaluasi secara forensik.

\section{SIMPULAN}

Perubahan histologik berupa perubahan morfologik inti disertai degenerasi hidropik mulai tampak pada 2 jam postmortem dan pada 24 jam postmortem perubahan tersebut sudah terdistribusi luas. Walaupun demikian, corak seran lintang masih dapat diidentifikasi dengan baik sampai 24 jam postmortem dan juga terdapat area jaringan otot jantung yang masih tampak normal.

Penelitian ini diharapkan dapat memberikan kontribusi terhadap kepentingan medikolegal di masa depan dalam mengungkapkan saat kematian dini.

\section{SARAN}

Penelitian ini dilakukan dari 15 menit hingga 24 jam postmortem dengan pengambilan sampel di seluruh area otot jantung. Untuk peneliti selanjutnya disarankan untuk menggunakan durasi waktu yang lebih lama dan pengambilan sampel pada area otot jantung yang lebih spesifik. 
DAFTAR PUSTAKA

1. Maslichah S, Suryani M. Analisis pengaruh faktor internal dan eksternal penyebab timbulnya tindakan kriminal dengan pendekatan simulasi serta sistem dinamika ntuk mengurangi angka kriminalitas. Jurnal Teknik Pomits. 2012; 1:1-2.

2. Azmi NA. Modus operandi kejahatan pencurian kendaraan bermotor roda dua (Studi di Polresta Malang) [Skripsi]. Malang: Universitas Brawijaya; 2014.

3. Astuti NW. Analisis tingkat kriminalitas di kota Semarang dengan pendekatan ekonomi tahun 2010-2012 [Skripsi]. Semarang: Universitas Diponegoro; 2014.

4. Darmadi AASMY. Kebijakan hukum pidana mempertahankan jenis pidana mati (Studi kasus pembunuhan berencana disertai mutilasi) [Tesis]. Denpasar: Universitas Udayana; 2015.

5. Tanatologi. 2010 [cited: 2014 Nov 12] Available from: fkunand2010.files.wordpress.com/tha natologirk.ppt

6. Thanatologi. 2008 [cited: 2014 Nov 15] Available from: elib.fk.uwks.ac.id/asset/archieve/matk ul/20PBL/Tanatologi.pdf.

7. Cel injury, cel death and adaptation. 2003 [cited: 2015 Apr 08]. Available from: www.newagemedical.org/celldeathinjury-link2.pdf.

8. Robbins Buku Ajar Patologi (7th ed). Jakarta: EGC, 2012; p. 3-33.
9. Gunanti, Siswandi R, Soehartono RH, Ulum MF, Sudisma IGN. Pembiusan babi model laparaskopi untuk manusia dengan xoletyl, ketamin dan xylazin. Veteriner. 2011; 12(4):247-53.

10. Degenerasi dan nekrosis. 2013 [cited 2015 Apr 03]. Available from: http://www.slideshare.net/KampusSakinah/degenerasi-dan-nekrosis

11. Degenerasi dan kematian sel. 2013 [cited 2015 Apr 03]. Available from: http://www.slideshare.net/septianraha /3-degenerasi-dan kematiansel?related $=1$

12. Sudiono J, Kurniadhi B, Hendrawan A, Djimantoro B. Perubahan Patologi Sel dan Jaringan (1st ed). Jakarta: EGC, 2003; p. 13-30.

13. Pratama A. Hubungan antara lama waktu kematian dengan kerusakan histopatologik otot jantung tikus wistar. [Skripsi]. Semarang. Universitas Diponegoro; 2010.

14. Prasojo H. Hubungan lama kematian dengan kerusakan histopatologis otot gastrocnemius tikus wistar [Skripsi]. Semarang: Universitas Diponegoro; 2010.

15. Schoen FJ, Mitchell RN. In: Klatt EC, Kumar R, Mitchell RN, editors. Robbins Basic Pathology (9th ed). Kanada: Elsevier Saunders, 2013; p. 380.

16. Rahmadana B. Gambaran histologik ginjal hewan coba postmortem [Skripsi]. Manado: Universitas Sam Ratulagi; 2014. 